\title{
ROLE OF SAR DATA IN WATER BODY MAPPING AND RESERVOIR SEDIMENTATION ASSESSMENT
}

\author{
Prasad N.R. ${ }^{*}$, Vaibhav Garg ${ }^{2}$ and Praveen K. Thakur ${ }^{2}$ \\ ${ }^{1}$ Agriculture and Soils Department, Indian Institute of Remote Sensing, Indian Space Research Organisation, 4, Kalidas Road, Dehradun \\ - prasad007nr@gmail.com \\ ${ }^{2}$ Water Resources Department, Indian Institute of Remote Sensing, Indian Space Research Organisation, 4, Kalidas Road, Dehradun -
} (vaibhav, praveen)@iirs.gov.in

Commission V, SS: Natural Resources Management

KEY WORDS: Geospatial technology, Sentinel-1A, reservoir capacity, reservoir sedimentation, SAR

\begin{abstract}
:
Reservoir sedimentation is the major problem, due to it every year the reservoir capacity is lost to considerable amount. Surveying for assessment of the reservoir by conventional approach is time and money consuming. Geospatial technology provides ample opportunity in this field through the availability of high resolution satellite data from sensors such as Sentinel, Indian Remote Sensing Satellite, Landsat, and SPOT have been used to calculate the water spread area of the reservoir. However, due to presence of cloud in most of the optical data during onset of monsoon, the water spread at the lowest reservoir level could not be mapped. In turn the revised capacity or sedimentation is generally assessed between either below full reservoir level (FRL) or above maximum draw down level (MDDL). Nowadays, the microwave synthetic aperture radar (SAR) data at reasonable spatial resolution is available freely in public domain. Moreover, microwave data has capability to penetrate cloud and the information below cloud can easily be retrieved. To overcome the issues related to optical data, in the present study, the reservoir sedimentation for Ghataprabha reservoir was estimated using SAR data. Sentinel-1A data was used to delineate the water spread area for the water year of 2016-17. The original live storage capacity (1974) was estimated to be $1434.14 \mathrm{Mm}^{3}$ at FRL $662.940 \mathrm{~m}$ by the authorities using the hydrographic survey during the commissioning of the reservoir in the year 1974. The live storage capacity was found out to be $1366.14 \mathrm{Mm}^{3}$ at FRL, however, as per original elevation-area-capacity curve the live capacity is around $1262.404 \mathrm{Mm}^{3}$ at $660.50 \mathrm{~m}$. Estimated live storage capacity from Remote sensing approach (2016-17) was assesses as $1182.5 \mathrm{Mm}^{3}$ at $660.51 \mathrm{~m}$. The storage capacity has reduced from $1262.40 \mathrm{Mm}^{3}$ (1974) to $1182.51 \mathrm{M} \mathrm{m}^{3}$ i.e. around $171.732 \mathrm{Mm}^{3}$. As per present analysis the rate of sedimentation is around $4 \mathrm{Mm}^{3} / \mathrm{yr}$. It was realized that using the SAR microwave data, the revised capacity of the reservoir from its near MDDL to FRL could be assessed through remote sensing approach.
\end{abstract}

\section{INTRODUCTION}

Reservoir sedimentation is the filling up of repository behind the dam with sediments or residues, which leads to loss in the capacity of the reservoir. Sedimentation is unstoppable process but can only be controlled through suitable measures upstream reservoir catchment. Sedimentation in reservoirs is the major constraint to ensure safety of dams, energy production and flood threat. It is occurring at a faster rate than expected for which the reservoirs was constructed for initial, it has become faulty. Its estimation is very much important to know the changing elevation in the reservoir capacity. According to Mahmood (1987) as roughly estimated that around $50 \mathrm{~km}^{3}$ of sediment i.e. nearly one percent of global storage capacity of reservoir is deposited in the world's reservoir each year. The sedimentation rate is largely depended on the size of the reservoir. It mainly affects the turbines in the reservoir, this may cause huge repair expenses. The problem with the sedimentation is that sediments do not deposit evenly on a horizontal plane due to this live storage capacity is reduced before filling up of the dead storage. A case study conducted in Pakistan Tarbela Reservoir (1992) shows that 12 percent of live storage capacity was lost even though dead storage capacity of 55 percent was empty (McCuully,
1996). Estimation of reservoir capacity through conventional survey is tedious; time and money consuming. These surveys are often exposed to constraints like unpredicted monsoons, forest fires, wildlife, and limited accessibility (Chowdary et al., 2017). The sedimentation has become a major problem in Indian Reservoirs due to various problem like population growth, agricultural activities, deforestation and poor soil conservation practices. A survey has revealed that an average of about 200 percent more sediment is received by Indian reservoirs than they are designed for inflow (Tejwani, 1984). Reduction in the reservoir capacity decreases reliability and flexibility of water supply. Shortage in water leads to reduction in hydropower generation especially when the dependency is on seasonal flow (lean period) The impact of sedimentation on environment has detrimental effect. Increase in sedimentation creates turbid water which in turn have negative impact on aquatic life. It is also a primary carrier of suspended pollutants like phosphorus, nitrogen and heavy metals into the water (Hydro world, 2017). Moreover, the estimation of revised elevation capacity is indeed a big task for authorities.

The remote sensing technique may assist in overcoming of these problems. So there is a need for use of geospatial technology in reservoir sedimentation for providing data within a short period of

${ }^{*}$ Corresponding author 
time. Reservoir survey and capacity estimation through remote sensing is gaining importance now a days through high resolution images of LANDSAT, SPOT, IRS and Sentinel etc. data (Jain et al., 2002; Goel, Jain, \& Agarwal, 2002; Pandey et al., 2016; Foteh et al., 2018). Through Remote Sensing multi-temporal, spatial and spectral data can be obtained at near real time. The availability of high resolution satellite images in public domain, now made the calculation of water spread area for estimating reservoir sedimentation more accurate. Both optical and microwave data has been used to derive the water spread area in several studies (Bates et al. 2006; Alsdorf et al. 2007, Khaba \& Griffiths, 2017). Till date for calculating the reservoir sedimentation mostly optical data has been used from different EO (Earth Observation) missions. Since most of the time optical data is covered by clouds, it's difficult to obtain images for calculating water spread area of the reservoir during the highest and lowest level of the reservoir i.e. during monsoons. Microwave data provides an alternative to this problem, since SAR images provides all time weather free data. Surface water of Cambodia and Vietnamese Delta has been monitored using Sentinel-1 SAR (Synthetic Aperture Radar) data. The estimated surface water maps of SAR data has compared to Landsat- 8 water surface water maps it has showed a positive water detection. The study reveals that Sentinel-1 SAR data has the capability of surface water monitoring is very much useful in tropical areas to get cloud free data (Pham-Duc, Prigent, \& Aires, 2017).

This study focuses on assessment of reservoir sedimentation using SAR data rather than optical data. The Ghataprabha reservoir in the state of Karanataka having an area of $<70 \mathrm{~km}^{2}$ was assessed for estimation of reservoir capacity and sedimentation as well. Using microwave data spread area is assessed for capacity estimation.
Later, the trapezoidal formula to calculate the capacity at each elevation on the date of satellite pass was used. As the analysis provides capacity at different water elevation, the revised elevationcapacity curve was also drawn. The change in original capacity and the present time capacity is regarded as volume of sediments deposited.

\section{STUDY AREA}

Ghataprabha reservoir is constructed on Ghataprabha waterway between $16^{\circ} 9^{\prime} 0^{\prime \prime} \mathrm{N}$ Latitude and $74^{\circ} 38^{\prime} 0^{\prime \prime}$ E Longitude in Hukkeri Taluk, Belgaum District of Karnataka state as shown in Figure 1. The reservoir is situated in the Upper Krishna basin. The prime purpose of the reservoir is irrigation. The first phase of store comprised of $71 \mathrm{~km}$ long left bank waterway from the Dupdal weir was built in 1897 crosswise over Ghataprabha River for giving water system to a degree of 0.425 lakh ha in Gokak channel. Second stage comprised of an expansion of left bank channel of $72 \mathrm{~km}$ to full length of $109 \mathrm{~km}$ the supply level was $650.14 \mathrm{~m}$ making a capacity of $659 \mathrm{Mm}^{3}$ giving water system to a zone of 1.39 lakh ha including zone under first stage. Third Reservoir level was raised to $662.94 \mathrm{~m}$ which has made a capacity of $1448 \mathrm{Mm}^{3}$ and gave a region of 3.31 lakh ha for water system. The FRL of the Ghataprabha Reservoir $662.94 \mathrm{~m}$ and MDDL is $633.292 \mathrm{~m}$. The Gross limit of the supply is around $1434.136 \mathrm{Mm}^{3}$ (waterresources.kar.nic.in). The designed live storage capacity of the reservoir was estimated as $1366.14 \mathrm{Mm}^{3}$, however, according to the hydrographic survey of the year 2000 , it has reduced to $1277.15 \mathrm{Mm}^{3}$. The rate of siltation was calculated as $4.46 \mathrm{Mm}^{3} / \mathrm{yr}$ against the designed rate of siltation of $0.58 \mathrm{Mm}^{3} / \mathrm{yr}$.
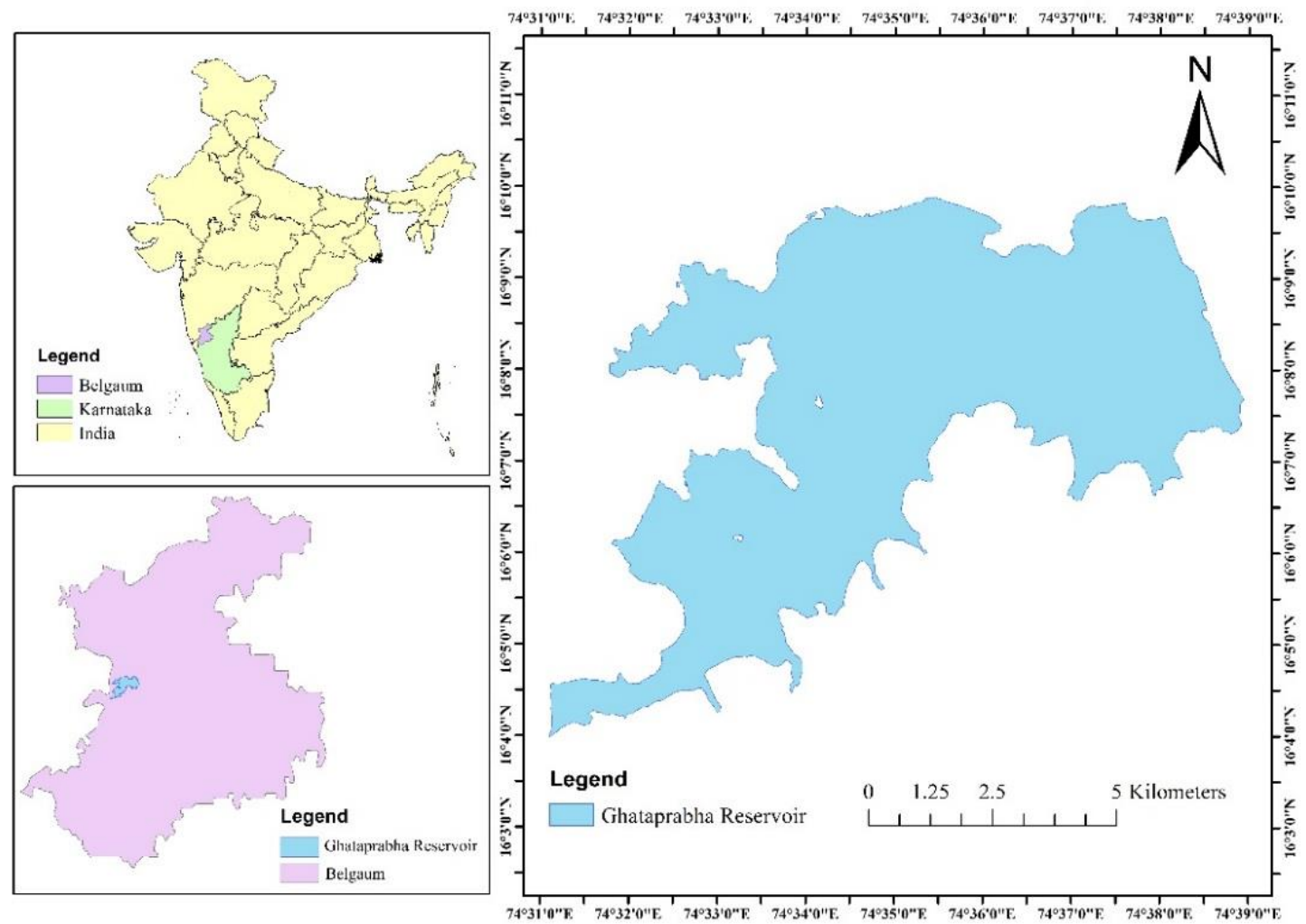

Figure 1. Location of Ghataprabha Reservoir and its water spread area 


\section{MATERIALS AND METHODOLOGY}

As discussed earlier, all the reservoirs are subjected to sedimentation which reduces its useful storage. The sedimentation cannot be fully stopped, however, regular monitoring of the reservoirs can provide important information on capacity lost to sedimentation. However, the sedimentation assessment through hydrographic surveys are costly and time consuming. Therefore, in the present study, the alternate remote sensing technique has been utilized for assessing the sedimentation in the Ghataprabha reservoir. The reservoir level gradually decreases to its minimum level at the end of May or June month and remains near FRL during monsoon period. The remote sensing provides water spread of any water body on the surface of the earth at regular interval. So, the water spread of a reservoir can be mapped using remote sensing data for any water year on different dates. Knowing the water level of the reservoir, its capacity can be assessed through trapezoidal formula. Therefore, the sedimentation assessment was carried out for water year from June 2016 to May 2017. The calculation of water spread area for the present analysis the Sentinel-1 SAR data was used. The reservoir water level data of the corresponding satellite images was acquired from India Water Resources Information System (India-WRIS) (http://www.indiawris.nrsc.gov.in/). The overall methodology adapted is shown as flow chart in Figure 2.

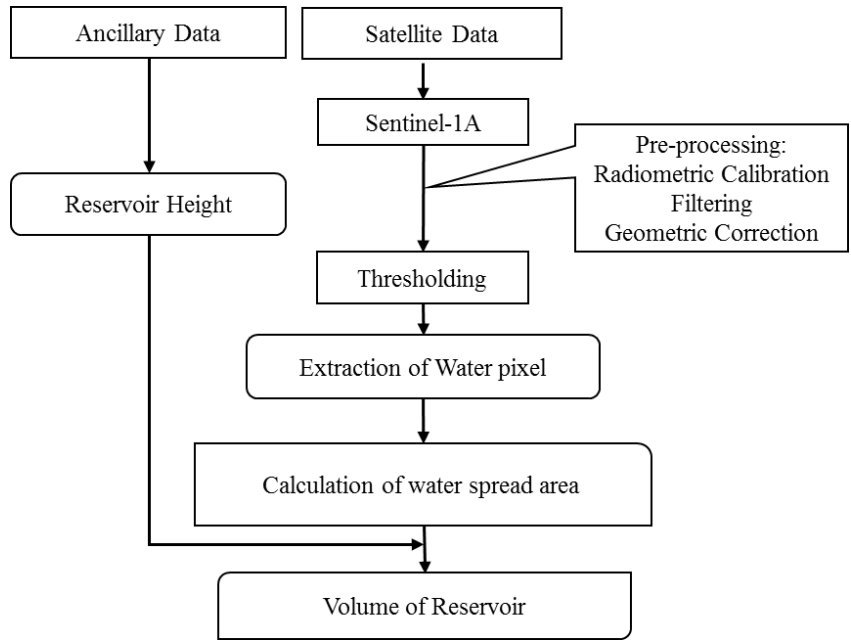

Figure 2. Overall Methodology flow chart

\subsection{SAR Microwave Data and Its Processing}

The water spread area is monitored using microwave data. Here Sentinel-1A SAR operating at C-band data was used which was launched by European Space Agency during April 03, 2014. It is having repeat period of 12 days. Sentinel-1A ground range detected (GRD) data was obtained from Copernicus-sentinel hub (https://scihub.copernicus.eu/dhus/) which is open platform for all the sentinel data. The reservoir is at FRL (Full Reservoir Level) during monsoon period that is at October and drops down to MDDL at onset of monsoon that is during May and June. So SAR data is best suited to calculate the water spread area during the lowest and highest level of reservoir, which is generally missed by optical data due to presence of cloud. SAR data was pre-processed in Sentinel Application Platform (SNAP) for radiometric calibration, speckle filtering, geometric correction and sigma nought $(\sigma 0)$ image (true backscatter image). In SAR image the deep stagnant water will have low backscatter as compare to other features due to specular reflection. Therefore, the water pixels will appear darker in colour with respect to other features on the image, those can easily be identified. The water pixels were extracted using VV \& VH polarization through thresholding approach as shown in Figure 3. In the present study, the threshold was found out to be -15 for VV \& -21 for $\mathrm{VH}$ as also given in Table 1 . Then the water image was exported to ArcGIS for vectorization and to calculate the water spread area. As the SAR data was resolved at $10 \mathrm{~m}$ spatial resolution, the water spread area was calculated by multiplying the number of water pixels with pixel area.

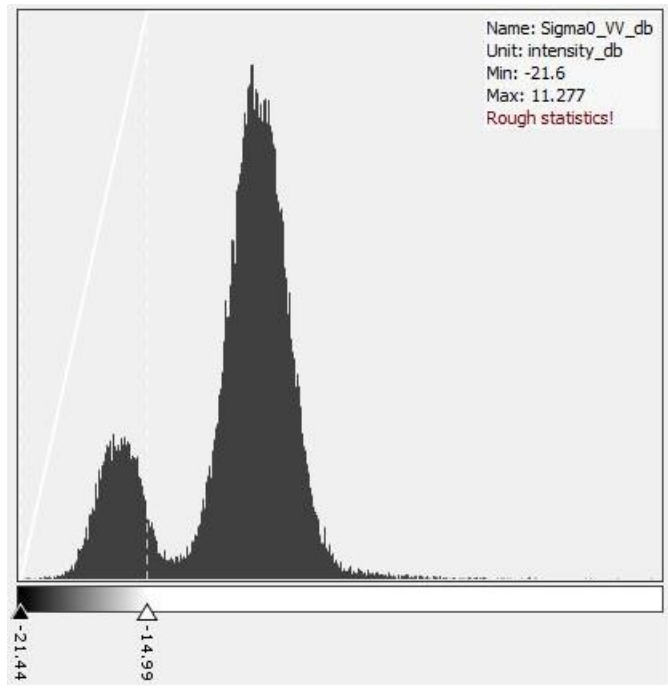

Figure 3. Procedure of selecting threshold on VV Polarized image

\begin{tabular}{|c|c|c|c|}
\hline $\begin{array}{c}\text { Date } \\
4 / 10 / 2016\end{array}$ & Threshold & Polarization & $\begin{array}{c}\text { Reservoir } \\
\text { Height }\end{array}$ \\
\hline $16 / 10 / 2016$ & -21 & VH & 659.89 \\
\hline $28 / 10 / 2016$ & -15 & VV & 660.46 \\
\hline $21 / 11 / 2016$ & -15 & VV & 660.51 \\
\hline $3 / 12 / 2016$ & -15 & VV & 656.67 \\
\hline $15 / 12 / 2016$ & -15 & VV & 629.10 \\
\hline $27 / 12 / 2016$ & -15 & VV & 655.11 \\
\hline $8 / 1 / 2017$ & -15 & VV & 654.14 \\
\hline $20 / 1 / 2017$ & -15 & VV & 651.43 \\
\hline $1 / 2 / 2017$ & -15 & VV & 649.76 \\
\hline $13 / 2 / 2017$ & -15 & VV & 649.67 \\
\hline $9 / 3 / 2017$ & -15 & VV & 646.60 \\
\hline $21 / 3 / 2017$ & -15 & VV & 641.04 \\
\hline $2 / 4 / 2017$ & -15 & VV & 640.92 \\
\hline $14 / 4 / 2017$ & -15 & VV & 640.79 \\
\hline $8 / 5 / 2017$ & -15 & VV & 638.96 \\
\hline $20 / 5 / 2017$ & -15 & VV & 632.71 \\
\hline & & &
\end{tabular}

Table 1. Satellite data acquisition dates, threshold used for extraction of water spread area and reservoir water level on each day 


\subsection{Estimation of Live Storage Capacity of the Reservoir}

Calculation of live storage capacity of reservoir involves creation of database, calculation of water spread area from the SAR data, daily observed data for reservoir height for the satellite pass dates (Chowdary et al., 2017). The basic principle of assessing the sedimentation using remote sensing approach is that the water spread at particular elevation will reduce due to the sediment deposition with time (Goel et al., 2002). Considering the volume stored between two dates or elevation as trapezoid (as shown in Figure 4), the capacity between these two elevations can easily be calculated using the trapezoidal formula.

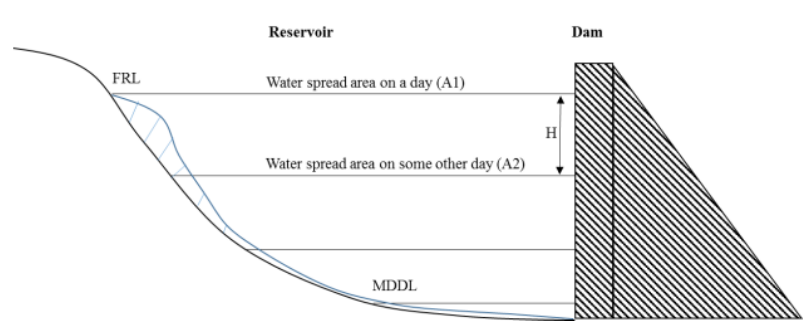

Figure 4. Sedimentation profile in a reservoir

Trapezoidal method has been used to estimate the volume of reservoir in this study as given in eq. 1 .

$$
V=\frac{H}{3} *\left(A_{1}+A_{2}+\sqrt{A_{1} * A_{2}}\right)
$$

Where, $V$ is the capacity of the reservoir between two elevations, $A_{1}$ and $A_{2}$ are the water spread area at these two elevations or two dates of satellite pass. $\mathrm{H}$ is the elevation difference between two elevations of the respective dates. The corresponding reservoirs height for dates of satellite data pass were obtained from IndiaWRIS. Cumulative revised live storage capacity is calculated by adding all the capacity at each elevation under consideration. Difference between the original and revised capacity gives total sediment deposition between the lowest and highest observed elevations.

\section{RESULTS AND DISCUSSION}

\subsection{Extraction of water spread area using SAR data}

As the principle of remote sensing approach of reservoir sedimentation suggests the accurate water spread area calculation is very much important. The advantage of using SAR data over optical data is to extract the water spread area during its lowest level just at the time of onset of the monsoon. During this time period most of the time the surface of the earth is covered by the clouds. It is also mentioned earlier that the reservoir attains its maximum level just after the monsoon and reach to lowest level just before the onset of the monsoon. Therefore, in the present study, the
Ghataprabha Reservoir sedimentation has been assessed through remote sensing approach for the water year 2016-17 using Sentinel1 SAR data. All the SAR data mentioned for this water year in Table 1 was analysed as discussed in the methodology for extraction of water spread. The maximum water spread of the reservoir was found to be $64.0 \mathrm{~km}^{2}$ on October 28, 2016 and the lowest was $15 \mathrm{~km}^{2}$ on May 08, 2017 correspond to their water levels on the respective dates as shown in Figure 5.
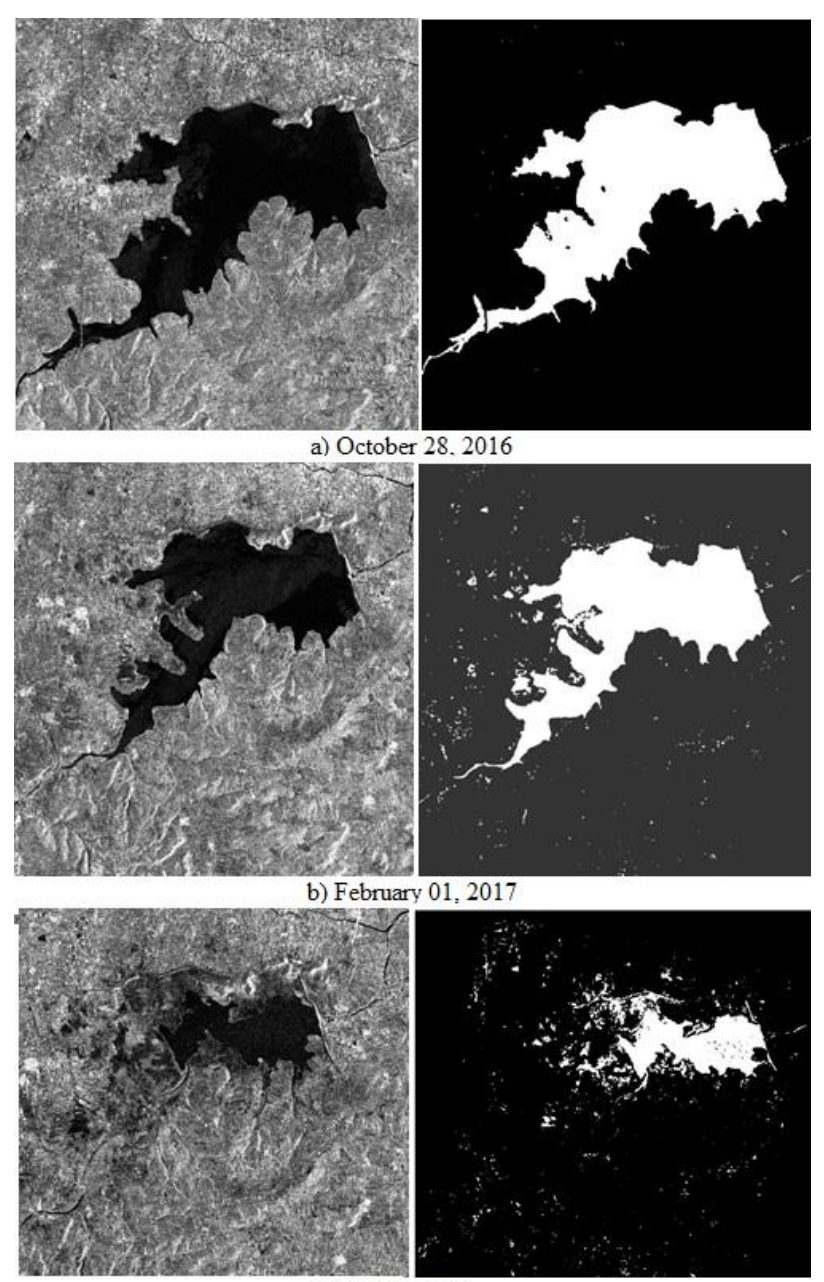

c) May 20,2017

Figure 5. Water pixel extracted from Sentinel-1A data of Ghataprabha reservoir

SAR data images were available for maximum dates almost one in each month unlike optical data. The extracted water spread area of each date under consideration for the water year 2016-17 is provided in the Table 2 and Figure 6 . It is to be noted that while extracting the water spread using SAR data, a care must be taken as there are chance of miscalculation of water spread due to ripples/waves on water surface which increases its roughness and backscatter as well. To overcome these problem one has to set threshold by analyzing both VV and VH polarization. 


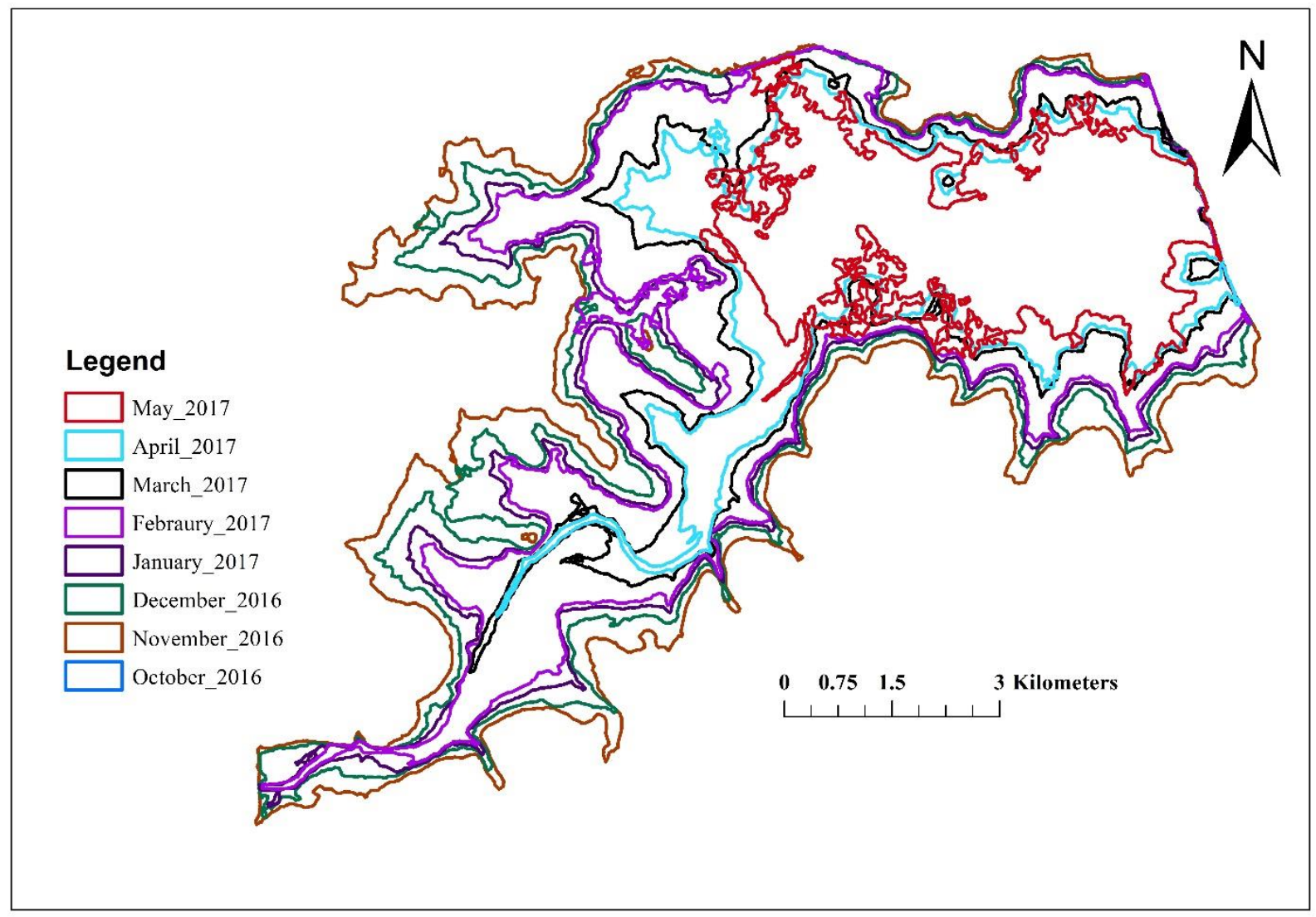

Figure 6. The change in water spread area of the reservoir during water year 2016-17 extracted from Sentinel-1 data

\subsection{Reservoir Capacity Estimation}

The water spread obtained from Sentinel-1A SAR data for each date under consideration was then used to estimate revised live storage capacity of the reservoir. Considering the volume between two elevation or satellite pass as trapezoid, the volume of the reservoir is calculated using the Trapezoidal formula as described in methodology section. The capacity obtained between each elevation was used to calculate the cumulative live storage capacity of the reservoir. The results of the entire analysis are presented in Table 2. The estimated cumulative live storage capacity of the reservoir at $660.50 \mathrm{~m}$ height from Sentinel-1A data was found out to be $1182.51 \mathrm{Mm}^{3}$ (2016-17), however, Ghataprabha reservoir has original live storage capacity of $1262.4 \mathrm{Mm}^{3}$ at $660.5 \mathrm{~m}$ reservoir level according to commissioning year 1974 hydrographic survey data. The change in original and the revised capacity may be regarded as volume of sediments deposited, which comes around $171.732 \mathrm{Mm}^{3}$. This useful capacity is lost during a period of 43 years, which result in rate of sedimentation as around $4 \mathrm{Mm}^{3} /$ year. The estimated sedimentation rate is very high as compare to designed rate of siltation i.e. $0.58 \mathrm{Mm}^{3} /$ year. However, it is very close to the results of hydrographic survey carried out in the year 2000 , which estimated the rate of sedimentation as $4.4 \mathrm{Mm}^{3} /$ year.

This the advantage of remote sensing approach that it also gives water spread and capacity at different reservoir levels on the date of pass of satellite. The revised water spread and capacity at each elevation can be used to draw revised elevation-capacity curve. The information is very important for reservoir authorities from reservoir operation point of view. The obtained water spread area was compared with the original water spread area at different elevations of the reservoir to know the changing water spread area of the reservoir at each elevation. The elevation-capacity curve derived from remote sensing approach using the SAR data was plotted against the original elevation-capacity curve of the reservoir as shown in Figure 7. There was shift in the curve as compared to the original elevation-capacity of the reservoir. It was found that the capacity has reduce almost each elevation, further, the reduction in capacity is higher on the high elevation. 


\begin{tabular}{|c|c|c|c|c|}
\hline Date & $\begin{array}{c}\text { Area } \\
\left(\mathbf{k m}^{\mathbf{2}}\right)\end{array}$ & $\begin{array}{c}\text { Reservoir Height } \\
(\mathbf{m})\end{array}$ & $\begin{array}{c}\text { Capacity } \\
\left(\mathbf{M m}^{\mathbf{3}}\right)\end{array}$ & $\begin{array}{c}\text { Cumulative Capacity } \\
\left(\mathbf{M m}^{\mathbf{3}}\right)\end{array}$ \\
\hline $03 / 12 / 2016$ & 54.78 & 629.1 & & 121.86 \\
\hline $20 / 05 / 2017$ & 16.46 & 632.71 & 121.86 & 126.10 \\
\hline $08 / 05 / 2017$ & 15.01 & 632.98 & 4.25 & 237.80 \\
\hline $14 / 04 / 2017$ & 22.61 & 638.96 & 111.70 & 282.74 \\
\hline $02 / 04 / 2017$ & 26.56 & 640.79 & 44.94 & 286.21 \\
\hline $21 / 03 / 2017$ & 26.81 & 640.92 & 3.47 & 289.44 \\
\hline $09 / 03 / 2017$ & 27.04 & 641.04 & 3.23 & 466.13 \\
\hline $13 / 02 / 2017$ & 36.76 & 646.6 & 176.68 & 589.81 \\
\hline $01 / 02 / 2017$ & 43.92 & 649.67 & 123.68 & 593.78 \\
\hline $20 / 01 / 2017$ & 44.29 & 649.76 & 3.97 & 666.49 \\
\hline $08 / 01 / 2017$ & 46.95 & 651.43 & 76.18 & 806.37 \\
\hline $27 / 12 / 2016$ & 53.81 & 654.14 & 136.42 & 858.83 \\
\hline $15 / 12 / 2016$ & 54.35 & 655.11 & 52.45 & 946.48 \\
\hline $21 / 11 / 2016$ & 58.05 & 656.67 & 87.65 & 1142.71 \\
\hline $04 / 10 / 2016$ & 63.88 & 659.89 & 196.23 & 1179.32 \\
\hline $16 / 10 / 2016$ & 64.60 & 660.46 & 36.62 & 1182.56 \\
\hline $28 / 10 / 2016$ & 64.88 & 660.51 & 3.24 & \\
\hline
\end{tabular}

Table 2. The results of reservoir sedimentation assessment of Ghataprabha Reservoir using remote sensing approach

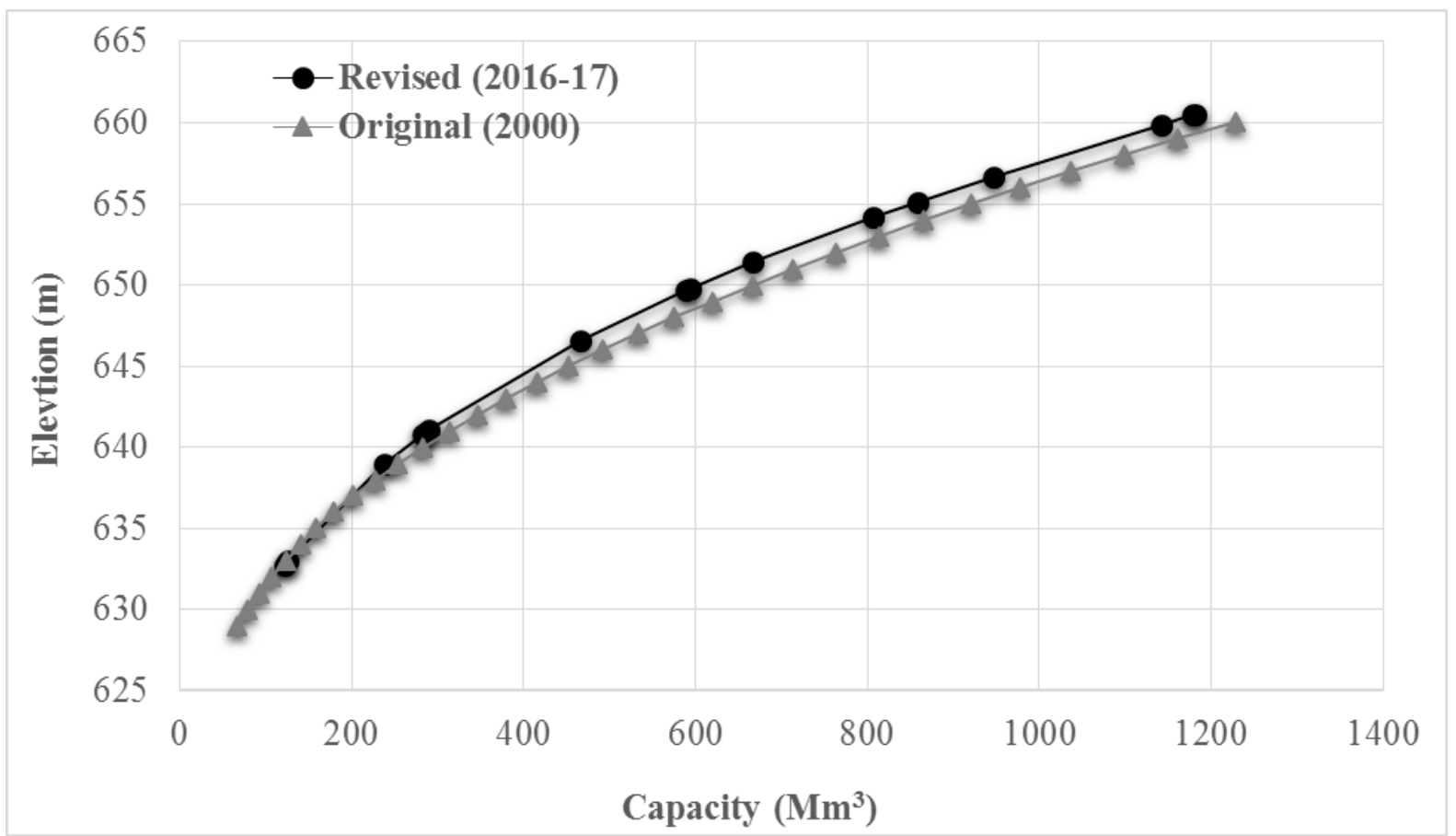

Figure 7. Comparison between Revised and Original Elevation-Capacity Curve of the Reservoir

\section{CONCLUSION}

Sedimentation of the reservoirs is accelerating year by year; the frequent floods, soil erosion, deforestation, and change in land cover pattern all have aggravated the problem at a higher rate. Conventional surveys are not possible to be carried out frequently for large reservoirs in estimating sedimentation because of their cost and time consuming nature. Remote sensing techniques are filling the gap to provide the near real time data so that preventive measures can be taken in time. It is to be noted that through remote sensing approach the capacity of the reservoir may be assessed only for live storage as it is not necessary that the reservoir level will 
down even below its MDDL. However, the interest of dam authorities lies in live storage only, as it is the water that is going to be used for the purpose the reservoir was constructed. Till date, mostly the optical data has been utilized for assessing sedimentation of reservoirs using remote sensing approach. However, as these datasets are affected by presence of cloud most of the time in a year, the user left with very few dataset for the analysis. It is generally difficult to map the water body at its lowest level using optical data, as the water body reaches to it minimum level just before the onset of the monsoon. Furthermore, SAR data provides cloud free data so the information such as change in water spread for entire time period can be obtained, even for the lowest level of the reservoir. SAR data is weather free data so we can obtain the images during monsoon season also and it has 12 day repeat cycle.

The water spread area was delineated from Sentinel-1A for different dates of water year 2016-17 and the corresponding reservoir water level obtained from India WRIS was used to calculate revised live storage capacity of the reservoir. The revised live storage capacity between elevations from 632.71 to $660.51 \mathrm{~m}$ was assess as $1182.56 \mathrm{Mm}^{3}$. It was compared with the original capacity of the reservoir estimated in the year 1974 through most accurate hydrographic survey method as $1262.40 \mathrm{Mm}^{3}$. Reservoir live capacity loss was found out to be $171.732 \mathrm{Mm}^{3}$ and the sedimentation has occurred at the rate of $4 \mathrm{Mm}^{3} / \mathrm{yr}$ in these 43 years. As remote sensing approach also provides capacity of reservoir at different reservoir level, it was used to draw the revised elevation-capacity curve of the reservoir, which is an important input for dam authorities. The revised elevation-capacity curve shows that capacity of the reservoir has reduced at almost each elevation due to sedimentation.

It was realized that the SAR data are more capable in assessing the sedimentation in a reservoir for entire range of live storage. SAR data can be used to extract water spread with higher accuracy, which is a prime requisite of remote sensing approach to assess sedimentation. Moreover, the high repeat period of Sentinel-1 (around 06 days considering both Sentinel-1A \& B) makes its ideal sensor for mapping water spread at very close interval, which further improves sedimentation assessment (reduces the error in considering the volume between two dates as trapezoid). Further, it has its own processing platform SNAP, which makes its processing easy and user friendly. It is to be noted that the remote sensing approach can be used as substitute to hydrographic surveys, however, the capacity or sedimentation assessment will always be more accurate through hydrographic surveys. Keeping in mind the cost and time required for the hydrographic surveys, it is recommend that these surveys can be done at large interval, whereas, sedimentation assessment through remote sensing approach can be carried out at shorter time interval. There is need of remote sensing based studies to be conducted on other reservoirs also.

\section{ACKNOWLEDGEMENTS}

The authors would like to thank the Copernicus Open Access Hub (previously known as Sentinels Scientific Data Hub) for providing the Sentinel-1 data for the study free of cost.

\section{REFERENCES}

Alsdorf, D.E., Rodriguez, E., Lettenmaier, D.P., 2007. Measuring surface water from space. Rev Geophys. 45(2):1-24. doi:http://dx.doi.org/10.1029/2006RG000197

Bates, P.D., Wilson, M.D., Horritt, M.S., Mason, D.C., Holden, N., Currie, A., 2006. Reach scale floodplain inundation dynamics observed using airborne synthetic aperture radar imagery: data analysis and modelling. J Hydrol. 328(1-2):306-318.

Berry, P.A.M., Garlick J.D., Freeman J.A., Mathers E.L., 2005. Global inland water monitoring from multi-mission altimetry. Geophys Res Lett. 32(16):L16401. doi:http://dx.doi.org/10.1029/2005GL022814

Birkett C.M,. 2000. Synergistic remote sensing of Lake Chad: variability of basin inundation. Remote Sens Environ. 72:218-236.

Calmant S., Seyler F., Cretaux J.F., 2008. Monitoring continental surface waters by satellite altimetry. Surv Geophys. 29:247-269.

Cauhope, M., Gennero, M.C., Dominh, K., Cretaux, J.F., BergeNguyen, M., Cazenave, A., Seyler, F., 2006. Worldwide validation of satellite altimetry based water level time series (EgU06-A02342, HS52). Wien (Australia): EGU General Assembly. [cited 2006 April 02-07].

Chowdary, V.M., Sai Krishnaveni, A., Suresh Babu, A.V., Sharma, R.K., Rao, V.V., Nagaraja, R., Dadhwal, V.K., 2017. Reservoir capacity estimation using SARAL/AltiKa altimetry data coupled with Resourcesat P6-AWiFS and RISAT 1 microwave data. Geocarto International, 32(9), 1034-1047. https://doi.org/10.1080/10106049.2016.1188165

Coe M.T., Birkett C.M., 2004. Calculation of river discharge and prediction of lake height from satellite radar altimetry:example for the Lake Chad basin. Water Resour Res. 40:W10205. doi:http://dx.doi.org/10.1029/2003WR002453

Cretaux J.F., Birkett C., 2006. Lake studies from satellite radar altimetry. CR Geosci. 338:1098-1112.

Deng, X., Featherstone, W.E., 2006. A coastal retracking system for satellite radar altimeter waveforms: Application to ERS-2 around Australia. Journal of Geophysical Research: Oceans. https://doi.org/10.1029/2005JC003039

Frappart F., Calmant S., Cauhope M., Seyler F., Cazenave A., 2006a. Validation of ENVISAT RA-2 derived waterlevels over the Amazon Basin. Remote Sens Environ. 100:252-264.

Frappart F., Do Minh K., L'Hermitte, J., Cazenave, A., Ramillien, G., Le Toan, T., Mognard- Campbell, N., 2006b. Water volume change in the lower Mekong from satellite altimetry and imagery data. Geophys J Int. 167:570-584.

Foteh, R., Garg, V., Nikam, B.R., Khadatare, M.Y., Aggarwal, S.P., Senthil Kumar, A. 2018. Reservoir Sedimentation Assessment through Remote Sensing and Hydrological Modeling. Journal of the Indian Society of Remote Sensing, https://doi.org/10.1007/s12524-018-0843-6 
Ghosh, S., Kumar Thakur, P., Garg, V., Nandy, S., Aggarwal, S., Saha, S. K., ... Bhattacharyya, S., 2015. SARAL/AltiKa Waveform Analysis to Monitor Inland Water Levels: A Case Study of Maithon Reservoir, Jharkhand, India. Marine Geodesy. https://doi.org/10.1080/01490419.2015.1039680

Goel, M.K., Jain, S.K., Agarwal, P.K., 2002. Assessment of sediment deposition rate in Bargi Reservoir using digital image processing. Hydrological Sciences Journal. Special Issue: Towards Integrated Water Resources Management for Sustainable Development. https://doi.org/10.1080/02626660209493024

Jain, S.K., Singh, P., Seth, S.M., 2002. Assessment of sedimentation in Bhakra Reservoir in the Western Himalayan region using remotely sensed data. Hydrological Sciences Journal, 47(2):203-211.

Khaba, L., Griffiths, J.A., 2017. Calculation of reservoir capacity loss due to sediment deposition in the 'Muela reservoir, Northern Lesotho. International Soil and Water Conservation Research. https://doi.org/10.1016/j.iswcr.2017.05.005

Leon J.G., Calmant S., Seyler F., Bonnet M.P., Cauhope M., Frappart F., 2006. Rating curves and average water depth at the upper Negro river from satellite altimetry and modelled discharges. J Hydrol. 328:481-496.

Mahmood, K., 1987. Reservoir sedimentation: Impact, Extent, Mitigation, Technical Rep. No. 71, World Bank, Washington, D.C.

McCully, P., 1996. Sedimentation Problems with Dams. International Rivers.

Michailovsky C.I., McEnnis S., Berry P.A.M., Smith R., Bauer Gottwein P., 2012. River monitoring from satellite radar altimetry in the Zambezi River Basin. Hydrol Earth Syst Sci. 9:3203-3235.

Pandey, A., Chaube, U.C., Mishra S.K., Kumar D., 2016. Assessment of reservoir sedimentation using remote sensing and recommendations for desilting Patratu Reservoir, India, Hydrological Sciences Journal, 61(4):711-718.

Pham-Duc, B., Prigent, C., Aires, F., 2017. Surface water monitoring within cambodia and the Vietnamese Mekong Delta over a year, with Sentinel-1 SAR observations. Water (Switzerland). https://doi.org/10.3390/w9060366

Rapley C.G., 1990. Satellite radar altimeters. In: Vaughan RA, editor. Microwave remote sensing for oceanographic and marine weather-forecast models. Norwell (MA): Kluwer Acad.; p. 45-63.

Saikrishnaveni, A., Chowdary, V.M., Dutta, D., Sharma, J.R. Dadhwal, V.K., 2016. SARAL/AltiKa altimetry data for monitoring of inland waterbody: a case study of Mayurakshi reservoir, India. J. Indian Soc Remote Sens. https://doi.org/http:// dx.doi.org/10.1007/s12524-015-0535-4

Tang Q.H., Gao H.L., Lu H., Lettenmaier D.P., 2009. Remote sensing: hydrology. Prog Phys Geogr. 33:490-509. doi: http://dx.doi.org/10.1177/0309133309346650

Tejwani, K.G., 1984. Reservoir sedimentation in India? its causes, control, and future course of action. Water International. https://doi.org/10.1080/02508068408686525

\section{WEB LINKS}

Water Resources Karnataka. Salient Features of Ghatprabha Reservoir http://waterresources.kar.nic.in/salient_features_ghataprabha

India Water Resources Information System - http://www.indiawris.nrsc.gov.in/

Sentinel data Hub - https://scihub.copernicus.eu/dhus/ 